\title{
ANÁLISE CRÍTICA DA PUBLICIDADE: UM ESTUDO SOBRE ANÚNCIOS DE MEDICAMENTO
}

\author{
(Critical analysis of advertising: a study \\ on drug advertisement)
}

\author{
Viviane Ramalho ${ }^{1}$ \\ (Universidade de Brasília - UnB)
}

\begin{abstract}
In this paper we ponder about potentially ideological meanings in medicine advertising texts through a Critical Discourse Analysis' approach (Chouliaraki \& Fairclough, 1999; Fairclough, 2003). From the analysis of text "Na Hora H, conte conosco", we start discussing the emergence of new "discursive technologies". In other words, it is the strategic manipulation of the language guided for domination. The conclusions show that specific implicit meanings found in medicine advertising can help to support popular ideologies, as well as to disseminate anxieties regarding health.
\end{abstract}

Keywords: discourse; ideology; drug advertisement.

\section{RESUMO}

Neste trabalho realizamos uma reflexão, à luz da Análise de Discurso Crítica (Chouliaraki \& Fairclough, 1999; Fairclough, 2003a), sobre sentidos potencialmente ideológicos no gênero "anúncio publicitário de medicamento". A partir da análise do texto "Na Hora H, conte conosco", discutimos a emergência de "tecnologias discursivas". Isto é, de manipulações estratégicas da linguagem orientadas para projetos de dominação. As conclusões apontam que certos sentidos implícitos que circulam em anúncios de medicamento podem sustentar ideologias naturalizadas, assim como instaurar anseios relacionados a saúde.

Palavras-chave: discurso; ideologia; anúncio de medicamento.

1 Professora Adjunta na UnB, onde realizou Mestrado e o Doutorado em Linguística. 


\section{Introdução}

Neste trabalho, apresentamos resultados da pesquisa Discurso e ideologia na propaganda de medicamentos: um estudo crítico sobre mudanças sociais e discursivas (Ramalho, 2008), desenvolvida no Programa de Pós-Graduação em Linguística da Universidade de Brasília. $\mathrm{O}$ objetivo geral do estudo, que deu origem ao projeto de pesquisa Representações da saúde na mídia², foi investigar o papel do discurso na sustentação de relações assimétricas de poder, sobretudo entre "peritos/ as" (especialistas em saúde: médicos/as, empresários/as da indústria farmacêutica; assim como especialistas em linguagem: publicitários/ as, editores/as de veículos de comunicação) e "leigos/as", cidadãos/ãs comuns, que recebem diariamente conteúdos publicitários e necessitam do conhecimento perito em saúde.

No Brasil, o debate sobre os riscos da circulação de propagandas de medicamento na mídia já é bastante consolidado. As preocupações envolvem, por exemplo, os riscos da automedicação, das intoxicações, do consumo inadequado e exagerado de medicamentos, da autoidentificação projetada na imagem do/a consumidor/a de produtos para saúde (Ramalho, 2008, 2009a). Tudo isso somado a desigualdades sociais e dificuldades de acesso a serviços e tratamentos de saúde, dentre outros problemas.

A indústria de medicamentos, que está entre as mais lucrativas do mundo, investe mais em propaganda do que em pesquisa e desenvolvimento de novos medicamentos, correspondendo a cerca de $35 \%$ da receita (Angell, 2007). Embora tenhamos no Brasil serviço público de saúde assim como políticas de regulação da promoção comercial de medicamentos, parte da população, por um lado, não tem

2 O Projeto de pesquisa Representações da saúde na mídia, desenvolvido no âmbito da Universidade de Brasília (UnB), integra as atividades do Grupo Brasileiro de Estudos de Discurso, Pobreza e Identidades, liderado pela pesquisadora Denize Elena Garcia da Silva (2007a, 2008, 2009). Um dos objetivos do projeto é investigar e problematizar representações hegemônicas da "saúde" na mídia impressa brasileira. 
acesso a tratamentos e serviços de saúde de qualidade. Por outro lado, considerável parcela da sociedade recebe diariamente apelos comerciais que possuem potencial para, em práticas específicas, levar pessoas ao consumo desnecessário e desmedido de medicamentos. Essa conjuntura problemática tem colocado a propaganda de medicamentos na agenda das discussões em Saúde Pública.

Desde 1980, vários estudos sobre a promoção comercial de medicamentos vêm sendo desenvolvidos no Brasil, sobretudo na área de Saúde Pública (Nascimento, 2007; Temporão, 1987). Apesar de envolver diretamente o uso da linguagem, até meados de 2005 a publicidade de medicamentos não era objeto de pesquisas linguísticodiscursivas, o que já se pode verificar em estudos como Böelke (2008), Silva e Coroa (2005), Silva (inédito), além do que apresentamos aqui. Na Análise de Discurso Crítica (ADC) de vertente britânica (Chouliaraki \& Fairclough, 1999; Fairclough, 2003a), encontramos suporte teóricometodológico adequado para investigar esse problema social que se sustenta principalmente pelo discurso.

Para apresentar resultados da pesquisa, organizamos este artigo em quatro seções, além da apresentação e das considerações finais: na primeira seção, discutimos brevemente a perspectiva teórica do estudo; na segunda, descrevemos a abordagem teórico-metodológica da ADC; na terceira seção, discutimos resultados da parte mais social do estudo, e, na quarta e última seção, apresentamos um exemplo de análise textual realizada na pesquisa.

\section{Perspectiva teórica da pesquisa: Análise de Discurso Crítica}

As diversas correntes de estudos do discurso têm em comum o foco na relação entre linguagem e poder. A diferença entre elas advém das perspectivas (filosóficas, epistemológicas, ontológicas) que as orientam. A própria Análise de Discurso Crítica, cuja motivação central 
é "investigar criticamente como a desigualdade social é expressa, sinalizada, constituída, legitimada pelo uso do discurso", é um campo heterogêneo de estudos e abarca ampla gama de perspectivas e filiações (Wodak, 2004: 225).

Conforme Magalhães (2005: 3; 2010), a ADC britânica difere das demais abordagens da área pela "criação de um método para o estudo do discurso e seu esforço extraordinário para explicar por que cientistas sociais e estudiosos da mídia precisam dos linguistas”. Na pesquisa em foco, inerentemente interdisciplinar, essa necessidade é explícita. Outra especificidade da ADC britânica está na operacionalização de princípios do Realismo Crítico na proposta de abordagem crítica explanatória de problemas sociais que envolvem linguagem (Ramalho, 2007, 2009b; Resende, 2009).

De acordo com o Realismo Crítico, para que a ciência social seja possível é preciso compreender o mundo como "estratificado, estruturado, diferenciado e mutável” (Bhaskar, 1998: 38). Como objetos de estudo, as estruturas naturais e sociais são diferentes. Ao contrário das primeiras, as estruturas sociais apresentam permanência apenas relativa e não existem independentemente das atividades que elas governam, bem como das concepções dos agentes sobre o que fazem. As propriedades que tornam sociedades possíveis objetos de conhecimento pressupõem ação humana e mutabilidade. Nessa perspectiva ontológica, o mundo é um sistema aberto, constituído por diferentes domínios (real, actual e empírico $)^{3}$ e por diferentes estratos que operam simultaneamente (físico, químico, biológico, econômico, semiótico etc.), cada qual com suas estruturas distintivas e mecanismos gerativos, causando efeitos imprevisíveis no mundo. O real é o domínio das estruturas; o actual é o domínio dos eventos realizados; e o empírico é o domínio dos eventos realizados e experienciados. Isso implica que só podemos ter acesso ao "real" e ao "actual" por meio do "empírico".

3 Os termos originais em Bhaskar (1998) são real, actual e empirical. Uma tradução de "actual", proposta por Resende (2009), é "realizado". 
Com base nessa concepção de mundo, a linguagem é entendida na ADC britânica como um estrato da realidade, o estrato semiótico, que constitui outros momentos não semióticos, assim como é constituído por eles. Daí a linguagem ser tanto constituída socialmente quanto constitutiva de "identidades, relações sociais e sistemas de conhecimento e crença” (Fairclough, 1995: 131), o que implica que "questões sociais são, em parte, questões sobre discurso" (Chouliaraki \& Fairclough, 1999: vii). A relação estrutura social-agência humana é captada no foco intermediário das práticas sociais. Como entidade intermediária, situada entre estruturas (mais estáveis) e eventos (mais flexíveis), redes de práticas sociais carregam traços tanto de estruturas mais abstratas quanto de eventos concretos (Resende \& Ramalho, 2005, 2006).

As práticas sociais são, dessa forma, o "ponto de conexão entre 'sociedade' e pessoas vivendo suas vidas” (Chouliaraki \& Fairclough, 1999: 21). O discurso se situa nesse nível intermediário, nas maneiras recorrentes, situadas temporal e espacialmente, pelas quais indivíduos mobilizam recursos da estrutura para (inter)agirem no mundo. A linguagem, nessa concepção, constitui todos os níveis do social. O trabalho com linguagem como prática social (discurso), e não só como estrutura (sistema semiótico) ou só como ação individual (textos), permite alcançar traços da articulação causalmente interdependente entre linguagem-sociedade, o que define a lógica relacional/dialética da análise crítica.

Como ciência crítica, a ADC ocupa-se de efeitos ideológicos (ou seja, a serviço da dominação, conforme Thompson, 2002) que sentidos de textos, como instâncias de discurso, podem ter sobre relações sociais, ações e interações, pessoas, mundo material. Esse foco de atenção insere a ADC no paradigma interpretativo crítico, pelo qual intenta oferecer suporte científico para estudos sobre a função do discurso na instauração, sustentação e superação de problemas sociais.

Com base nessa abordagem científica, preocupada com efeitos potenciais do discurso em lutas hegemônicas e relações de dominação, 
realizamos a pesquisa sobre a promoção comercial de medicamentos no Brasil.

\section{Delineamento teórico-metodológico do estudo}

$\mathrm{Na}$ pesquisa em discussão, buscamos responder às seguintes questões: (1) Há conexões entre mudanças sociais na promoção de medicamentos na modernidade tardia (vigilância, sociedade de consumo) e mudanças discursivas? Quais? (2) Que sentidos potencialmente ideológicos são articulados nos textos publicitários? Como são articulados? (3) A quais convenções discursivas leitores de textos publicitários recorrem para identificar publicidades de medicamento? Há leituras mais disciplinadoras e outras mais criativas?

Dada a perspectiva relacional-dialética do estudo e o objetivo crítico de investigar, e também desvelar, a função do discurso da publicidade na sustentação de relações desiguais de poder, foi necessário pesquisar não somente textos, mas também outros aspectos envolvidos no problema: interesses ideológicos, relações sociais, aspectos conjunturais. Além disso, para responder às questões de pesquisa, foi preciso coletar e analisar dados não só sobre a composição das publicidades em si, mas também sobre práticas de produção e recepção/consumo desses textos, o que demandou, além de vasta pesquisa bibliográfica, coleta de dados documentais formais e informais, e de dados quantitativos.

A pesquisa qualitativa demandou uma abordagem predominantemente documental, cujo principal material empírico foram documentos formais da mídia impressa, elaborados por publicitários, jornalistas. Coletamos 610 textos, produzidos de 1911 a 2006, que promovem medicamentos mais ou menos explicitamente. Com base numa compreensão mais sociológica dos gêneros discursivos (Bazerman, 2004), sistematizamos os textos coletados segundo um gradiente de hibridização de gêneros. Tendo em vista a ambivalência discursiva contemporânea entre informação e publicidade (Fairclough, 1989), 
sistematizamos os textos conforme seu propósito promocional, mais ou menos explícito, em quatro categorias gerais: publicidade clássica; publicidade indireta; publicidade institucional e publicidade oculta. Cabe esclarecer que as três últimas categorias (publicidade indireta, institucional e oculta) são provenientes da primeira versão da RDC 96/2008, um documento formal que compunha o corpus ampliado da pesquisa.

A categoria publicidade clássica inclui textos cujo propósito promocional é facilmente identificável, quer porque apresenta estrutura genérica mais fixa (título, texto, ilustração, slogan, assinatura), quer porque, em casos de hibridização com outros gêneros, não dissimula seu propósito estratégico. A categoria publicidade indireta, por sua vez, diz respeito a textos que, sem mencionar nomes comerciais, apresentam marcas, logotipos, cores, símbolos, fotos, indicações de uso, potencialmente capazes de identificar o produto farmacêutico. A categoria geral publicidade institucional engloba textos cuja finalidade parece ser a promoção de instituições, uma vez que não há menção a medicamentos. No entanto, por meio de marcas, logotipos, cores, símbolos, fotos, indicações de uso e outros recursos, promovem, de fato, produtos farmacêuticos. Difere da publicidade indireta porque aquela não exalta qualidades de empresas. Por fim, fazem parte da categoria publicidade oculta textos em que se omite ou se dissimula o caráter publicitário. Exemplos de todas as categorias de texto são discutidos em Ramalho (2008). Aqui, neste trabalho, discutiremos apenas a "publicidade institucional”, na quarta seção.

Depois de sistematizados, os dados documentais deram origem a um corpus principal composto por 13 textos e, posteriormente à aplicação de questionários de leitura (ver a seguir), delimitamos um corpus de 6 textos, representativos do gradiente "mais ou menos explicitamente promocional”. Para responder às questões de pesquisa, somamos à investigação da composição dos textos, comentada mais adiante, outros dois elementos atuantes em processos de significação: a produção e a recepção/consumo de textos. Aspectos diretamente relacionados à 
produção dos textos publicitários foram investigados em dados formais, como legislações vigentes, e, também, em dados informais. Estes, constituídos por notas de campo realizadas em eventos organizados para discussão da legislação específica, envolvendo diferentes atores sociais: empresários da indústria de medicamentos, autoridades federais, sanitaristas, editores, publicitários.

Para investigar aspectos da recepção dos textos do corpus principal, recorremos a aplicação de questionário aberto autoadministrado, seguido de categorização e quantificação de respostas, com questões acerca da(s) função(ões) do texto; de elementos discursivos relevantes para a identificação da(s) função(ões), e acerca do tema do texto. Nessa fase, os/as colabores/as da pesquisa, estudantes de Graduação da Universidade de Brasília, leram os 13 textos do corpus principal para responder aos questionários. Na quarta seção, comentaremos resultados referentes a um dos textos do corpus.

Por fim, para o estudo da composição dos textos, ou seja, para a análise textual, estabelecemos um diálogo teórico-metodológico entre a teoria da narratividade do texto publicitário (Vestergaard \& Schroder, 1994) e as categorias analíticas da ADC, inspiradas na Linguística Sistêmica Funcional (Halliday, 2004). Nas seções seguintes, comentamos resultados da pesquisa, sintetizando aspectos da análise conjuntural e apresentando um exemplo de análise textual realizada no estudo.

\section{Saúde e discurso no novo capitalismo}

Dada a compreensão dialética da relação linguagem-sociedade, estudos em ADC conjugam análise social e análise discursiva. O discurso é visto como um dos momentos da prática social, em constante relação dialética com outros momentos, que, portanto, também devem ser investigados. O discurso é um elemento da prática social que constitui outros elementos sociais assim como é constituído por eles, em relações dialéticas de articulação e internalização. Assim sendo, pela análise 
de amostras discursivas historicamente situadas podemos investigar a articulação (disciplinadora ou transformadora) de momentos como, por exemplo, relações sociais e ideologias no discurso (Resende \& Ramalho, 2006).

No estudo que apresentamos aqui, a abordagem de aspectos mais sociais demandou pesquisa bibliográfica em diferentes disciplinas: História, Ciências Sociais, Ciências da Saúde, Comunicação (Abreu, 2007; Bauman, 2001; Barros, 1995; Angell, 2007; Canclini, 2006, e outros). Resultados dessa análise confirmam que medicamentos são representados como "símbolos de saúde": a materialização de um conceito que, hoje, significa a busca incessante pela expansão do potencial corporal, assim como pela superação das naturais limitações humanas (Silva, 2000). Como Bauman (2001) confirma, se outrora "ter saúde" significava ser "empregável", hoje "ter saúde" significa estar "apto", isto é, ter um corpo indefinidamente flexível, absorvente, ajustável. A saúde entendida como um padrão delimitável cede, cada vez mais, lugar à “aptidão” (fitness), um ideal humanamente inalcançável. O corpo do "indivíduo consumidor" é representado como objeto de culto e investimento, alvo da oferta extensiva de produtos/serviços de saúde pelos meios de comunicação.

Mesmo em países em desenvolvimento como o Brasil, essa representação de saúde como "ideal humanamente inalcançável” é facilmente identificável na grande mídia. Ilustremos com os exemplos das matérias de capa da revista Superinteressante (ed. 271, nov. 2009), que apresenta a "Ṕlula da inteligência", e da revista Galileu (n. 220, nov. 2009), que anuncia "os novos limites do corpo", alcançados "com a ajuda da ciência.” Ressalte-se que ambas são revistas de "vulgarização da ciência”, e não especificamente revistas especializadas em saúde, ou seja, publicações em que matérias desse tipo seriam previsíveis.

Os exemplos, que evidenciam a atualidade da discussão, apontam para a disseminação do "culto ao corpo", alimentado na mídia não só pela publicidade mas também por reportagens, que, em princípio, seriam textos mais informativos do que promocionais/comerciais (Ramalho, 
2009a). Os resultados da pesquisa indicam que na "sociedade da informação”, cuja economia se baseia na produção, circulação e consumo de discurso (Fairclough, 2003a; 2003b), o culto ao corpo não se restringe ao físico. Acentuam-se cada vez mais exigências relacionadas a capacidade intelectual, de memorização de informação, por exemplo, como atesta a “pílula” anunciada na revista Superinteressante (Ramalho, 2010).

Nessa conjuntura em que mercadorias se tornam "símbolos de saúde”, a propaganda de medicamentos é submetida a controle sanitário no Brasil. A Agência Nacional de Vigilância Sanitária (Anvisa) é responsável por controlar o conteúdo desse tipo de divulgação comercial na mídia geral, não especializada, com amparo na Resolução de Diretoria Colegiada 102/2000 e na RDC 96/2008. O avanço mais notável da RDC 96/2008, que deverá substituir a legislação anterior, consiste na tentativa de coibir maneiras indiretas de promover medicamentos: "Parágrafo único: Fica vedado utilizar técnicas de comunicação que permitam a veiculação de imagem e/ou menção de qualquer substância ativa ou marca de medicamentos, de forma não declaradamente publicitária, de maneira direta ou indireta (...) (Anvisa, 2008).

Hoje estudiosos/as preocupados/as com a promoção comercial de medicamentos discutem nacionalmente, em convergência com as preocupações da RDC 96/2008, as novas maneiras dissimuladas de promover medicamentos na mídia. A legislação preocupa-se em acompanhar as mudanças discursivas, e sanitaristas reiteram a necessidade de proibir esse tipo de prática promocional, exacerbadamente lucrativo para alguns setores e igualmente ameaçador para a sociedade em geral.

A influência que a linguagem exerce nas práticas sociais atuais é amplamente reconhecida. Conforme Fairclough (2002), o novo capitalismo, da "sociedade da informação", envolve uma "reestruturação” das relações entre diferentes campos da vida social, e um "re-escalonamento" nas relações entre diferentes escalas da vida social. A primeira envolve, sobretudo, transformações que apontam para a colonização de outros campos sociais (político, educacional, artístico) pelo campo econômico. Um exemplo, nos termos da pesquisa, 
é o processo de mercadologização da saúde. A segunda envolve, sobretudo, transformações nas relações sociais em escala local para escalas globais. A importância da linguagem nessas mudanças está na sua centralidade no novo modo de produção capitalista. Essa economia baseada no conhecimento, na informação, favorece a ampla circulação de representações ideológicas, garantida não só por gêneros discursivos específicos do campo publicitário, uma vez que este coloniza outros campos e discursos.

Nesse contexto, o discurso da publicidade tem potencial para "inserir a massa da população no sistema capitalista de mercadoria, atribuindo aos indivíduos o legitimado, e até mesmo desejável, papel de consumidores" (Fairclough, 1989: 36). A publicidade coloniza outros campos sociais e cria uma ambivalência que compromete a distinção entre propósitos estratégicos e propósitos comunicacionais (Habermas, 2002), de forma tal que compromete a credibilidade entre o que é autêntico e o que é tecnologia discursiva. O discurso torna-se aberto a processos de tecnologização, isto é, de cálculo, manipulação e desenhos econômicos, com a finalidade de sustentar o sistema capitalista fundado no consumismo (Fairclough, 2001; 2002).

A extensão da lógica econômica a outros campos sociais sinaliza um sério problema de confiança no novo capitalismo, que, nos termos da pesquisa, envolve a distinção, no conjunto de discursos e "saberes" sobre saúde, entre o que é informação, conhecimento técnico autêntico e confiável, e o que é publicidade, discursos estrategicamente orientados para ampliar o consumo de medicamentos. Em determinadas práticas e contextos, a exposição a discursos ambivalentes sobre saúde pode representar uma maneira de grupos hegemônicos particulares sustentarem relações assimétricas de poder. Pessoas que confiam na correção de conhecimentos técnicos sobre saúde podem estar expostas a tecnologias discursivas, o que contribui para criar supostas "necessidades", desejos e anseios relacionados à saúde.

Além de ser um modo de representar o mundo e de agir nele, o discurso também é um modo de identificar a si mesmo e aos 
outros. Contribui para a constituição de modos particulares e sociais de ser, ou seja, para a formação de identidades sociais ou pessoais particulares. Castells (2001: 22) aponta que a identificação é, parcialmente, um processo de construção de significado, baseado em atributos culturais inter-relacionados que prevalecem sobre outras fontes de significado. No entanto, envolve aspectos não discursivos e, além disso, pode sofrer interferência de instituições dominantes, mas somente quando e se os atores as internalizam, construindo o significado de sua identidade com base nessa internalização. Assim sendo, uma conscientização linguística mais crítica pode trazer alguma contribuição para a resistência a discursos hegemônicos em processos de identificação.

Em consonância com Fairclough (1989) e Bauman (2001), Canclini (2006: 14, 29) observa, na América Latina, um deslocamento da identidade do/a cidadão/ã para a do/a consumidor/a. As transformações do capitalismo avançado, segundo o autor, apontam para um processo em que as identidades se organizam cada vez menos em torno de símbolos nacionais e passam a inspirar-se a partir do que propõem os meios de comunicação. Para muitos, as perguntas próprias dos/as cidadãos/ãs - "a que lugar pertenço e que direitos isso me dá, como posso me informar, quem representa meus interesses?”, são respondidas antes "pelo consumo privado de bens e meios de comunicação do que pelas regras abstratas da democracia ou pela participação em organizações políticas”. Isso leva o autor a considerar que as "nações", nesta conjuntura, são definidas por comunidades internacionais de consumidores. As identidades são configuradas no consumo, "naquilo que se possui, ou naquilo que se pode chegar a possuir”, o que mina o papel do/a cidadão/ã social e politicamente participativo/a, além de gerar uma multidão de excluídos/as. Nessa conjuntura, não é difícil reconhecer a potencial influência dos discursos hegemônicos sobre saúde, que informam e vendem simultaneamente, em processos de identificação projetados na imagem do/a consumidor/a de medicamentos. 


\section{Exemplo de análise: publicidade institucional?}

Conforme mencionado, para o estudo da composição dos textos, ou seja, para a análise textual, estabelecemos um diálogo teóricometodológico entre a teoria da narratividade do texto publicitário (Vestergaard \& Schroder, 1994) e as categorias analíticas da ADC. Com base em análises-piloto, construímos um arcabouço para análise textual relacionando esforços retóricos característicos de textos publicitários (chamar atenção/despertar interesse; despertar desejo/criar convicção; induzir à ação) a categorias analíticas, que constituem recursos discursivos potencialmente capazes de levar a cabo tais esforços. Tendo em vista a plasticidade dos textos publicitários, ao contrário de trabalharmos com uma tipologia mais fixa (imagem/foto, texto verbal, slogan, assinatura) optamos por investigar nos textos "esforços retóricos", como o de "despertar interesse do/a leitor/a”, e recursos linguístico-discursivos ligados a eles, como interdiscursividade e valor da informação em imagens, por exemplo.

Textos são concebidos na ADC como parte de eventos específicos, que envolvem pessoas, (inter-)ação, relações sociais, mundo material e discurso. A análise textual focaliza a interface entre ação/relação, representação e identificação, os três principais aspectos do significado, permitindo não só abordar os textos, como material empírico, “em termos dos três principais aspectos do significado, e das maneiras como são realizados em traços dos textos", mas também fazer "a conexão entre o evento social concreto e práticas sociais mais abstratas”, pela investigação dos gêneros, discursos e estilos utilizados, e das maneiras como são articulados em textos (Fairclough, 2003a: 28). Daí deriva a característica explanatória da análise, que conjuga teoria e material empírico para investigar "como o momento discursivo trabalha na prática social, do ponto de vista de seus efeitos em lutas hegemônicas e relações de dominação" (Chouliaraki \& Fairclough, 1999: 67). Nos termos da pesquisa, investigamos se discursos particulares articulados em publicidades (representação) são legitimados no gênero publicidade de 
medicamento (ação/relação), e inculcados em estilos de vida projetados na imagem do/a consumidor/a de medicamento (identificação).

$\mathrm{O}$ texto que selecionamos para discutir aqui foi coletado em um espaço público, em Brasília/DF, no ano 2006. Àépoca, o controle sanitário da propaganda de medicamentos era exercido há seis anos, e a Anvisa já elaborava a nova legislação, RDC 96/2008. Como mencionamos, esse regulamento atual busca coibir as inovadoras técnicas publicitárias "não-ostensivas", a exemplo da suposta "publicidade institucional", apresentada a seguir:

Figura 1 - "Na hora H, conte conosco" (2006)
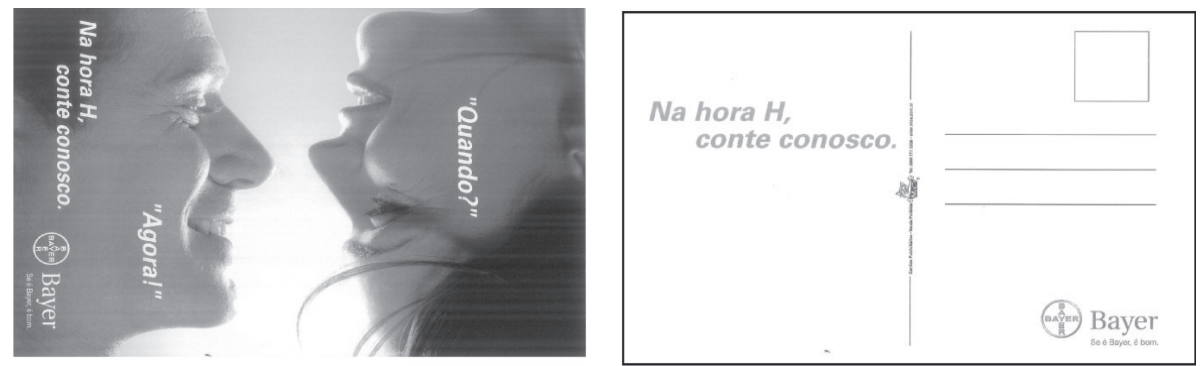

Fonte: Distribuição gratuita.

O texto, designado aqui como "Na hora $\mathrm{H}$, conte conosco", é uma amostra de publicidade conhecida no meio especializado como mídia card, um gênero que vem se consolidando na prática publicitária. De acordo com Sampaio (2003: 107), os "postais distribuídos em bares e restaurantes" são uma mídia extensiva, complementar aos veículos básicos de comunicação. Constituem, ainda segundo o autor, uma das tendências da publicidade, resultante da atual "necessidade de desenvolver novos formatos". Se a publicidade como um todo demanda formatos inovadores, no caso das propagandas de medicamento essa necessidade amplia-se. O formato mídia card contribui não só para atingir de maneira mais eficiente o/a leitor/a, mas também para fazê- 
lo de modo que não seja, ao menos imediatamente, percebido como propaganda de medicamento pelos/as legisladores/reguladores/as.

No livro Reclames da Bayer (2006), em que, posteriormente à coleta de dados, o texto foi publicado, essa propaganda é apresentada como "institucional". Significa que, segundo o anunciante, o texto em análise é uma propaganda dos laboratórios Bayer, e não do medicamento Levitra, imitação do Viagra patenteado pela Pfizer. "Imitação" significa que, findada a vigência da patente do medicamento, ele pode ser produzido por outros laboratórios. Como são muitas as imitações, só mesmo a propaganda, como observou Angell (2007), pode destacar uma ou outra marca concorrente. Conforme a autora, nos EUA, país em que esse tipo de prática publicitária é liberada, a propaganda de medicamentos para disfunção erétil é amplamente disseminada, espalhando-se por todos os espaços possíveis, incluindo estádios de futebol. No Brasil, apesar de ser proibida pelo fato de a venda do produto depender de receita médica (Anvisa, 2008), essa propaganda é feita, por exemplo, por meio de supostas "campanhas de utilidade pública”, como discutimos na pesquisa, e, também, por "publicidades institucionais”, como se pretende o texto em análise. A seguir, para investigar sentidos potencialmente ideológicos tendo em vista a interface entre ação/relação, representação e identificação, analisamos o texto segundo seis categorias linguístico-discursivas, quais sejam: estrutura visual e valor da informação, mais relacionadas ao esforço retórico da publicidade de chamar atenção/despertar interesse; interdiscursividade e metáfora, ligadas ao esforço de despertar desejo/criar convicção, e contato visual e hibridismo de gêneros, mais relacionadas ao esforço de levar à ação. Além disso, comentamos brevemente resultados da pesquisa sobre práticas de leitura do texto.

\subsection{Estrutura visual e valor da informação}

Na seção 2, definimos publicidade institucional como aquela cuja finalidade parece ser a promoção de instituições, uma vez que não há menção direta a medicamentos. No entanto, por meio de marcas, 
logotipos, cores, símbolos, fotos, indicações de uso e outros recursos, promovem produtos farmacêuticos. Conforme esclarecemos acima, para o anunciante o texto " $\mathrm{Na}$ hora $\mathrm{H}$, conte conosco" é uma "publicidade institucional", cuja finalidade única, portanto, seria promover o laboratório. Uma vez que, em princípio, não promove medicamentos, esse tipo de publicidade é permitido. Entretanto, numa leitura um pouco mais crítica e contextualizada na conjuntura de crescente conversão do medicamento em "símbolo de saúde", é possível identificar várias sugestões, tanto em modalidade verbal quanto visual, ao próprio medicamento Levitra produzido pela Bayer, e não só ao laboratório que o produz.

Assim como textos analisados na pesquisa que exploram a cor azul do medicamento Viagra, também no texto em análise (no original) a cor laranja do Levitra parece servir de recurso alusivo ao medicamento. Além da cor que remete ao produto, temos a representação particular dos participantes, assim como a atribuição de valores específicos às informações, como recursos para a construção de sentidos implícitos.

Como Silva (2007b) explica, na LSF a função ideacional da linguagem, relacionada a maneiras como experienciamos e representamos o mundo, associa-se ao sistema lexicogramatical da transitividade. Nesse sistema, selecionamos processos (grupos verbais) materiais, comportamentais, mentais, verbais, relacionais e existenciais, que são associados a diferentes papéis de participantes (grupos nominais) em diferentes circunstâncias (grupos adverbiais). De acordo com Halliday (2004: 172), os processos principais são os materiais, pelos quais se representam ações, eventos; os mentais, que representam percepções, emoções; e os relacionais, que identificam, caracterizam participantes. Os secundários, que se encontram nas fronteiras entre os principais, são os comportamentais, que representam comportamentos humanos; os verbais, que representam ações de dizer, pronunciamentos, e, por fim, os existenciais, que representam o que existe. A análise das seleções particulares de processos de transitividade em textos permite investigar as maneiras como o locutor representa aspectos do mundo. 
Com base na LSF, Kress \& van Leeuwen (1996) propõem uma abordagem teórico-metodológica para análise crítica de textos multimodais, ou seja, textos que conjugam diversos modos de linguagem. $\mathrm{Na}$ "gramática da linguagem visual", que descreve os modos culturalmente definidos como imagens se articulam em composições visuais, as imagens são concebidas em termos das mesmas macrofunções da linguagem verbal: ideacional, interpessoal e textual ${ }^{4}$. A exemplo da linguagem verbal, as imagens atuam como forma de representação, como troca de experiência e como mensagem. Entretanto, o que na linguagem verbal é realizado, por exemplo, por diferentes classes e estruturas semânticas, na linguagem visual realiza-se por diferentes cores, estruturas composicionais. O design visual como representação pode ser analisado segundo dois tipos de estrutura: narrativa e conceitual, conforme discutiremos na análise. Ainda de acordo com Kress \& van Leeuwen (1996), a macrofunção textual do design visual, como mensagem, pode ser investigada segundo o valor da informação. Essa categoria diz respeito à localização dos elementos visuais nas diversas zonas da composição imagética - esquerda e direita, superior e inferior, centro e margem -, que lhes confere valores de informação específicos.

No texto em análise, embora sejam poucos os elementos de composição textual, uma leitura possível é de que a representação dos participantes - mulher e homem na faixa etária dos 40 anos (idade que também é sugerida pela imagem) - conjugue traços das estruturas narrativas do tipo reacional e mental. Conforme Kress e van Leeuwen (1996), estruturas visuais que representam ações, eventos, processos de mudança, arranjos espaciais transitórios são narrativas. O que caracteriza uma estrutura como narrativa é a presença de um vetor, uma linha imaginária, formada por corpos, braços, linha do olhar, instrumentos em ação, dentre outros, que sugere ações, eventos. O tipo de vetor, a quantidade e os tipos de participantes envolvidos definem os processos

4 Para uma discussão sobre a operacionalização das macrofunções da LSF em ADC, $c f$. Resende \& Ramalho, 2005, 2006. 
narrativos como: processos de ação, processos reacionais, processos verbais, processos mentais e processos de conversão.

No texto, temos estruturas narrativas do tipo reacional, sinalizada por vetores formados pela linha dos olhos; e do tipo mental, indicada pelos pensamentos. Como não há balões de pensamento nem de fala delimitando os elementos verbais constituídos pela pergunta "Quando?" e pela resposta “Agora!”, não podemos afirmar com precisão se o casal manifesta esses elementos como "verbiagem", mensagem de balões de fala, ou como "fenômeno", mensagem característica de balões de pensamento. O que importa é a representação dos participantes em termos de fenômenos mentais, e não materiais, de ação, por exemplo. Isso se explica pelo fato de tanto o processo reacional transacional, em que um participante projeta a linha do olhar ao outro, quanto os processos mental e verbal, em que o participante emite um pensamento/ fala, implicarem representação dos participantes segundo (a verbalização de) seus conhecimentos, percepções, desejos, emoções, conforme a LSF.

Observa-se que a distribuição das informações na imagem explora o eixo horizontal. Na frente do mídia card, temos a imagem, de acordo a estrutura típica de cartão-postal. Na imagem, a mulher, à direita, conforme se sugere, projeta o vetor, formado pela linha do olhar, ao homem. Ela representa o experienciador (reacter), aquele que experiencia o processo de "sentir", e o homem, por sua vez, representa o fenômeno, o alvo da percepção feminina. Outro indício de que o ponto de partida da informação seja a mulher diz respeito ao fato de ser ela quem lança a pergunta, de modo a sugerir que é ela quem age sobre o homem e dele espera algo. O homem, à esquerda, compartilha espaço com as informações consideradas mais importantes. Além de estar mais visível ao leitor - ao contrário da mulher, que está de cabeça para baixo -, divide espaço com os elementos mais importantes para a publicidade: as referências comerciais - logotipo/assinatura "Bayer", e slogan "Se é Bayer, é bom”. Essa disposição, somada ao fato de o medicamento aludido ser indicado ao público masculino, sugere que o alvo do cartão publicitário são os homens. 
Em termos representacionais, mais ligados a discursos, essa organização semiótica particular sugere envolvimento sentimental e íntimo entre os participantes, que expressam desejos, emoções, sentimentos. É, notadamente, sugestiva ao ato sexual. Em termos identificacionais, constrói uma realidade em que a mulher moderna é quem cobra desempenho sexual do homem maduro, o consumidor potencial que, para atender a tal exigência social, ou para buscar autorrealização, ou para expandir seu potencial corporal, conforme Bauman (2001) e Silva (2000), pode “contar" com a Bayer, um dos laboratórios que produzem medicamento para disfunção erétil.

Em termos acionais, diretamente relacionados a gêneros, observase, por fim, que no verso do cartão, à esquerda, é reiterada a mensagem para o leitor "Na hora $\mathrm{H}$, conte conosco", ao passo que à direita estão, novamente, os elementos comerciais logotipo e slogan. Também é no verso do cartão que se observam tipificações mais marcadas do gênero “cartão postal”: os espaços reservados para o endereço do destinatário, para uma pequena mensagem do remetente e para o selo. Conforme Bazerman (2000), o cartão postal é um gênero característico da ordem de discurso interpessoal, e fruto de um processo de simplificação da carta pessoal. Nessa cadeia de gêneros, os “cartões publicitários”, podem ser vistos como um dos gêneros que evoluíram da carta pessoal, mas que hibridiza as ordens de discurso do mundo da vida e da publicidade. Esses cartões, segundo informações da agência pioneira nesse formato publicitário, teriam chegado ao Brasil no final de 1990, e hoje já estariam consolidados como veículo de baixo custo e amplo alcance.

O cartão publicitário, portanto, pode ter passado por um processo de constituição por hibridização genérica, mas hoje representa efetivamente um gênero em emergência; também criado a partir da carta pessoal, mas como resposta, num contexto social específico, à tendência de dissolução de fronteiras entre o mundo da vida o sistema da economia. As práticas publicitárias são amplamente informadas pelo conhecimento perito em linguagem, sobretudo no que diz respeito à recepção e aceitação do consumidor potencial. Assim sendo, no campo da 
publicidade exploram-se com frequência novos formatos, o que aponta para a insuficiência de abordagens científicas mais rígidas de tipologia textual, como ainda se verifica em alguns trabalhos sobre publicidade.

O texto em análise é um exemplo da publicidade praticada nos dias atuais, em que hibridismos de gêneros dão origem a novos formatos, orientados para alcançar o/a leitor/a potencial em situações mais espontâneas, em que a demanda à atividade de consumir não seja feita explicitamente. No que toca à promoção de medicamentos, a essa vantagem soma-se a possibilidade de dissimular o produto anunciado. Apesar das comentadas alusões ao Levitra; por não mencionar diretamente ao medicamento, o texto simula uma publicidade que teria como principal objetivo promover a indústria farmacêutica. Ocorre, no entanto, que o texto parece promover não só a instituição mas também seu produto, indicado para o público masculino e cuja publicidade é proibida pela Anvisa.

$\mathrm{Na}$ pesquisa, as análises indicaram que não se trata somente de publicidade institucional; temos, também, um exemplo de publicidade indireta, em que sugestões feitas por cores, símbolos, disposição de imagens, possibilitam a divulgação de medicamentos sem que estes sejam referidos de modo explícito. A análise permite dizer que a atratividade centra-se nos sentidos implícitos, que sugerem intimidade sexual entre o casal, assim como no estranhamento que pode ser causado pelo novo formato publicitário.

\subsection{Interdiscursividade e metáfora}

No que diz respeito aos recursos articulados no texto para persuadir o/a leitor/a, seja acerca das qualidades do produto anunciado, seja acerca das supostas vantagens de seu consumo, destacam-se a interdiscursividade e a metáfora.

A interdiscursividade consiste na hibridização em textos de discursos oriundos de diferentes ordens de discurso. É uma categoria que permite explorar a presença/ausência de discursos particulares, 
articulados de maneiras específicas, como parte de lutas hegemônicas, mas também como recurso para estimular desejo/criar convicção no leitor, no caso da publicidade. Constitui um traço moldado por discursos particulares, ligados a campos sociais, interesses e projetos particulares, por isso é um aspecto representacional do significado. Discursos particulares, como o científico, podem ser identificados pelo vocabulário ou seleção lexical, uma vez que "lexicalizam" o mundo de maneiras particulares (Fairclough, 2003a).

A metáfora, por sua vez, é, em princípio, um traço identificacional de textos, moldado por estilos particulares. Segundo Lakoff \& Johnson (2002), a essência da metáfora é "compreender uma coisa em termos de outra”. Como os autores observam, nosso sistema conceptual é metafórico por natureza, isto é, sempre compreendemos aspectos particulares do mundo, de acordo com nossa experiência física e cultural, em termos de outros aspectos, estabelecendo correlações. Os conceitos metafóricos que estruturam nossos pensamentos, ainda segundo os autores, também estruturam nossa percepção, nosso comportamento, nossas relações. As metáforas moldam significados identificacionais em textos, pois, ao selecioná-las num universo de outras possibilidades, o locutor compreende sua realidade e a identifica de maneira particular, orientada por aspectos culturais.

Como mencionamos, o cartão publicitário constitui um gênero emergente da publicidade que se origina da hibridização de convenções discursivas oriundas das ordens de discurso do mundo da vida e da publicidade. Elementos característicos da interação de tipo interpessoal mesclam-se a elementos tipificados de anúncios. Como parte dessa hibridização, opera-se um processo de interdiscursividade que converge com o conceito de "democratização sintética do discurso", uma tecnologia discursiva em que se eliminam assimetrias explícitas no discurso, tendo em vista finalidades ideológicas (Fairclough, 2001). Além das tipificações de um gênero associado em princípio ao mundo da vida, o texto também não ordena ao leitor que consuma o produto, mas cria, de maneira sintética, uma interação supostamente simétrica. Esse 
efeito é alcançado não só pela articulação de recursos da modalidade visual, mas também da modalidade verbal. A oferta "Na hora $\mathrm{H}$, conte conosco" sugere proximidade entre os interlocutores, assegurada pelo tom conversacional, que transforma uma ordem em um conselho amigável.

Este “conselho" constrói, ainda, uma relação em que o medicamento produzido pelo laboratório é representado como instrumento de guerra. Como se sabe, "hora H” é uma expressão característica da terminologia militar utilizada para referir a hora escolhida para dar início a operações de guerra. Aplicada para compreender outros conceitos, como o ato sexual, converte-se em metáfora de militarização. Esse uso figurado da linguagem, identificado em diversos textos do corpus da pesquisa, é frequente em anúncios, que representam a "doença" como inimigo, e o "medicamento" como o recurso bom e desejável, capaz de vencê-lo. Essa metáfora corrobora a estratégia ideológica de democratização do discurso, visto que o laboratório e o/a consumidor/a potencial, tanto da publicidade quanto do Levitra, são apresentados/as como "membros do mesmo exército" na luta contra a impotência sexual.

Outra importante representação metafórica típica de anúncios é a relação metonímica de "parte pelo todo", discutida em Lakoff \& Johnson (2002) e Eco (1997). No texto, o casal (parte) é apresentado como representante de sua classe ou categoria, isto é, de "todos os homens e mulheres modernos e com vida sexual ativa” (todo). O sentido que se constrói é o de que se o casal do anúncio, modelo a se copiar, é feliz porque consome Levitra, o/a leitor/a potencial, assim como todas pessoas representadas pelo par, também pode alcançar a felicidade pelo consumo do medicamento, o objeto que materializa os conceitos de saúde, felicidade, vigor. Tais sentidos atuam como estratégia ideológica de unificação, pelo fato de construírem simbolicamente uma forma de unidade que interliga indivíduos numa identidade coletiva, qual seja, a de consumidor/a de medicamentos (Thompson, 2002). Ainda como parte da estratégia de proximidade, podemos observar o tipo de contato visual estabelecido entre o par representado e o leitor. 


\subsection{Contato visual e hibridismo de gêneros}

Na gramática de Kress \& van Leeuwen (1996: 119), o design visual como troca de experiência, de acordo com a macrofunção interpessoal da linguagem, pode ser analisado segundo a categoria contato visual, dentre outras. Associadas a textos verbais ou sozinhas, imagens podem sugerir demandas em trocas de atividade, ou ofertas em trocas de conhecimento/ informação. Como explicam os autores, na comunicação visual o tipo de interação depende da natureza do contato visual estabelecido entre os participantes representados, isto é, pessoas, lugares, e coisas que são o assunto da comunicação, e os participantes interativos, que participam da comunicação, ou seja, "quem fala e ouve ou escreve e lê, produz as imagens ou as vê", o que inclui os leitores, ou viewers.

Nas imagens em que participantes representados olham diretamente para o leitor, vetores formados pela linha dos olhos conectam os primeiros com o leitor (viewer), participante interativo. Nessa configuração visual, o participante representado, de quem o vetor (linha do olhar) emana, dirige-se ao participante interativo e demanda algo dele. A troca estabelecida, neste caso, é de atividade. Por outro lado, nas configurações visuais em que o objeto do olhar não é o leitor, mas, sim, o participante representado, que é observado pelo viewer, não há contato direto entre os participantes representados e interativos. A troca é de conhecimento, por meio de ofertas, em que os participantes representados figuram como itens de informação, objetos de contemplação.

Como indicamos acima, no texto em análise a imagem do cartão publicitário sugere, pelo vetor que emana dos olhos e pela pergunta verbalizada ou mental, que a mulher age sobre o homem. Desse modo, os participantes representados é que interagem, e não demandam diretamente algo do/a leitor/a. Na composição textual, a única demandaé aquela insinuada ao/à leitor/a - "Na hora H, conte conosco" - como um conselho simétrico. No mais, a composição imagética sugere troca de conhecimento/informação. Conforme Kress e van Leeuwen (1996), nesse tipo de representação visual, não há contato direto entre os participantes representados e o/a leitor/a, o 
participante interativo. A troca é de conhecimento, por meio de ofertas, em que os participantes representados são oferecidos como itens de informação ou objetos de contemplação. Esses elementos verbais e visuais, ligados ao tipo de troca e contato visual estabelecido, corroboram a "democratização sintética do discurso", já identificada na interdiscursividade e nas metáforas do texto. A ordem velada, possibilitada no cartão publicitário pela articulação dos discursos do mundo da vida e da publicidade, constitui uma das estratégias para alcançar o/a leitor/a em situações de descontração. No caso específico da propaganda de medicamentos, constitui, ainda, estratégia para dissimular o propósito de promover o Levitra.

$\mathrm{O}$ que se verifica nesse tipo de hibridismo de gêneros, como em muitos outros textos do corpus da pesquisa, é um processo não só de intergenericidade, como entende Marcuschi (2005), mas, sim, de metáfora acional, ou seja, de uma maneira não-congruente de (inter-) agir, orientada para estabelecer e sustentar relações de dominação (Ramalho, 2008, 2009a). Observa-se que o uso de tipificações genéricas, como recursos disponíveis na rede de opções de ordens de discurso, não se presta apenas para "coordenar atividades e compartilhar significados pelo reconhecimento de maneiras recorrentes de interagir" (Bazerman, 2004: 316). Tal uso de convenções de gêneros discursivos pode estar revestido ideologicamente e funcionar como instrumento de luta hegemônica. Com base em Thompson (2002), podemos conceber esse tipo de tecnologia discursiva como uma estratégia de construção simbólica ligada ao modo de operação da ideologia por “dissimulação". Isto é, uma maneira não-congruente de inter-agir que pode servir para ocultar, negar ou obscurecer relações de dominação, favorecendo a ação ideológica sobre o outro, assim como a distribuição assimétrica de poder.

No texto em análise, a rearticulação estratégica de tipificações do cartão-postal contribui para dissimular propósitos promocionais, facultando a divulgação de propagandas de medicamentos. O cartão publicitário, como destacam pesquisas atuais do campo, permite alcançar o consumidor potencial cada vez mais "alfabetizado em publicidade". Se a "ordem" tende a ser rejeitada, a oferta de informações pode receber 
menos rejeição do público-alvo. Para o/a regulador/legislador/a da propaganda de medicamentos, o emergente formato publicitário pode representar mais um obstáculo para coibir a divulgação de medicamentos como a suposta "materialização da saúde".

Nota-se que os recursos discursivos utilizados para perseguir o esforço de atrair o leitor e "mascarar a ordem” em anúncios de produtos farmacêuticos avançam os de natureza lexicogramatical em direção a novas articulações de elementos de ordens de discurso. Comisso, queremos destacar a emergência do gênero cartão publicitário como instrumento e tendência de pressões sociais específicas, fundado na rearticulação de convenções de gêneros, discursos e estilos de diferentes campos (Silva \& Ramalho, 2008a, 2008b). É perceptível que a publicidade indireta do Levitra apoia-se mais em elementos visuais e tipificações discursivas trazidas de diferentes campos sociais do que propriamente em recursos lexicogramaticais (cf. Ramalho, 2006). Na subseção seguinte, trazemos alguns resultados sobre as práticas de leituras pesquisadas, a fim de confrontá-los com a análise textual.

\subsection{As práticas de leitura pesquisadas}

Nesta subseção, apresentamos dados sobre práticas de leitura do “cartão publicitário”. Cabe destacar que o texto em estudo é apenas uma amostra desse gênero; outros exemplares podem ser encontrados em Ramalho (2008).

As 30 respostas dos/as colaboradores/as à primeira questão do questionário de leitura, associada à Identificação da(s) função(ões) social(is) do texto, foram categorizadas em 3 itens (informar, vender e promover o laboratório), conforme as respostas abertas dos/as colaboradores/as leitores/as, e posteriormente quantificadas. A maioria (16 colaboradores/as) apontou a categoria Vender como principal função do texto lido, seguida de Promover o laboratório (8) e Informar (6). Os/as leitores/as-colaboradores/as da pesquisa, que representam uma população maior de leitores/as potenciais de cartões publicitários, reconhecem o texto como publicidade, voltada, sobretudo, para 
vender um produto farmacêutico, e não promover uma instituição. Aqueles que consideraram a possibilidade de o texto, principalmente, “informar” indicaram objetos de informação ligados a assuntos sexuais: "preservativos, remédios para impotência, contraceptivos", e outros. Isso sugere que sentidos implícitos do texto, acima discutidos, são identificados por essa seleção de leitores/as. Eles/as são capazes de inferir sentidos implícitos; recebendo, assim, o texto como uma publicidade.

Segundo as respostas aos questionários, os elementos discursivos em que se apoia tal leitura são os seguintes: Assinatura/logotipo (21 menções nas respostas); Slogan (13); Imagem sugestiva ao ato sexual (11); Linguagem informal (9), e Forma de cartão postal (5). Os dados sugerem que o texto não oferece dificuldades interpretativas aos/ às leitores/as. As convenções do cartão-postal, recontextualizadas no anúncio, não são associadas a práticas interpessoais, do mundo da vida, mas, sim, à prática publicitária. Assim como nos textos publicitários mais convencionais, os elementos mais citados nas respostas (Assinatura/ logotipo e Slogan) podem ser os responsáveis pela identificação da seguinte função predominante do texto, segundo os leitores: "vender um produto farmacêutico para melhorar a vida sexual”, para usar os termos de um/a colaborador/a.

Ao que tudo indica, a associação entre o anunciante "Bayer" e o produto "favorável à vida sexual” orientam a identificação do tema central do texto, conforme os/as colaboradores/as: Medicamento para problemas sexuais (17 respostas); Empresa Bayer (5); Saúde (4) e Problemas sexuais (4). Os dados confirmam a potencialidade da recepção do texto em análise como uma publicidade de medicamento, e não só como publicidade institucional, como alega a empresa divulgadora. Essas conclusões convergem com a observação de que a mudança social deixa inicialmente traços de elementos contraditórios ou inconsistentes nos textos. Entretanto, “à medida que conforma uma convenção discursiva emergente, o que é percebido pelos intérpretes, num primeiro momento, como textos estilisticamente contraditórios perde o efeito de 'colcha de retalhos', passando a ser considerado 'inteiro”" (Fairclough, 2001: 128). 


\section{Considerações Finais}

Neste artigo, discutimos resultados da pesquisa sobre a publicidade de medicamentos no Brasil - estudo que deu origem ao projeto, em desenvolvimento, Representações da saúde na mídia. As análises realizadas na pesquisa mais ampla, a exemplo desta que trazemos aqui, apontam que, como respostas a mudanças sociais, mudanças discursivas podem ter potencial ideológico, sobretudo no que tange à articulação estratégica de convenções de gêneros, discursos, estilos de diferentes campos sociais. Determinadas hibridizações de gêneros, a exemplo da analisada aqui, funcionam como tecnologias discursivas estrategicamente aplicadas para promover medicamentos de maneira dissimulada no contexto de vigilância. Ainda que o anunciante defina o texto "Na hora $\mathrm{H}$, conte conosco" como publicidade institucional, verificamos sua potencialidade para constituir também uma publicidade indireta, em que sugestões feitas por cores, símbolos, disposição de imagens, possibilitam a divulgação do medicamento sem que este seja referido de modo explícito, pelo menos até que o controle sanitário o identifique.

O estudo permitiu identificar e analisar o significativo papel do discurso da propaganda de medicamentos na sustentação de problemas sociais relacionados a distribuição desigual de poder entre "leigos/as" e "peritos/as". Representações hegemônicas particulares de grupos interessados na ampliação do mercado de consumidores/as de medicamento circulam em anúncios publicitários de modo a legitimar diversos problemas que são, em parte, efeitos ideológicos de (sentidos de) textos sobre relações sociais, ações e interações, conhecimentos, crenças, identidades. Isso somado, no Brasil, à grave diferenciação entre os podem e os que não podem "comprar saúde".

Recebido em: setembro de 2009 Aprovado em: novembro de 2009 VIVISEBBA@unb.br 


\section{Referências Bibliográficas}

Abreu, A. A. de \& Paula, C. J. de (Orgs.). Dicionário histórico-biográfico da propaganda no Brasil. Rio de Janeiro: FGV; ABP, 2007.

Angell, M. A verdade sobre os laboratórios farmacêuticos: como somos enganados e o que podemos fazer a respeito. Trad. Waldéa Barcellos. Rio de Janeiro: Record, 2007.

Anvisa. Resolução RDC $n^{\circ}$ 96, de 17 de dezembro de 2008. Disponível em: http://www.anvisa.gov.br/propaganda/rdc/rdc_96_2008_consolidada.pdf. Acesso em 30 nov. 2009.

Barros, J. A. C. de. Propaganda de medicamentos. Atentado à saúde? São Paulo: Hucitec/Sobravime, 1995.

Bauman, Z. Modernidade líquida. Trad. Plínio Dentzien. Rio de Janeiro: Jorge Zahar, 2001.

Bayer. Reclames da Bayer: 1943-2006. São Paulo: Carrenho, 2006.

Bazerman, C. Intertextuality: how texts rely on other texts. In: Bazerman, C. \& Prior, P. (ed.). What writing does and how it does it: an introduction to analyzing texts and textual practices. New Jersey: Lawrence Erlbaum, 2004, p. 83-96.

Bazerman, C. Letters and the social grounding of differentiated genres. In: Barton, D. \& Hall, N. (Ed.). Letter writing as a social practice. Amsterdam: John Benjamins, 2000, p. 15-30.

Bhaskar, R. Philosophy and scientific realism. In: Archer, M.; Bhaskar, R, et al. (Ed.). Critical realism: essential readings. London; New York: Routledge, 1998, p. 16-47.

Böehlke, R. de F. Constructing ideal body appearance for women: a multimodal analysis of a tv advertisement. Tese de doutorado. Universidade Federal de Santa Catarina. Programa de Pós-Graduação em Letras/Inglês e Literatura Correspondente, 2008.

Canclini, N. G. Consumidores e cidadãos: conflitos multiculturais da globalização. Trad. Maurício Santana Dias. Rio de Janeiro: UFRJ, 2006.

Castells, M. O poder da identidade. Trad. Klauss B. Gerhardt. São Paulo: Paz e Terra, 2001. 
Chouliaraki, L. \& Fairclough, N. Discourse in late modernity: rethinking Critical Discourse Analysis. Edinbourg: Edinbourg University, 1999.

Eco, U. A estrutura ausente: introdução à pesquisa semiológica. Trad. Pérola de Carvalho. São Paulo: Perspectiva, 1997.

Fairclough, N. Analysing discourse: textual analysis for social research. London; New York: Routledge. 2003a.

Fairclough, N. El análisis crítico del discurso como método para la investigación en ciencias sociales. In: Wodak, R. \& Meyer, M. (Comp.) Métodos de Análisis Crítico del Discurso. Barcelona: Gedisa, 2003b, p. 179-203.

Fairclough, N. Critical discourse analysis: papers in the critical study of language. New York: Longman, 1995.

Fairclough, N. Discurso e mudança social. Trad. (Org.) Izabel Magalhães. Brasília: Universidade de Brasília, 2001.

Fairclough, N. Language and power. London: Longman, 1989.

Fairclough, N. Language in New Capitalism. Discourse \& Society, mar., v. 13, p. 163-166, 2002.

Habermas, J. O discurso filosófico da modernidade. Trad. Luiz Sérgio Repa e Rodnei Nascimento. São Paulo: Martins Fontes, 2002.

Halliday, M.. A. K. An introduction to Functional Grammar. London: Hodder Arnold, 2004.

Kress, G. \& van Leeuwen, T. Reading images: the grammar of visual design: London; New York: Routledge, 1996.

Lakoff, G. \& Johnson, M. Metáforas da vida cotidiana. Trad. (coord.) Mara Sophia Zanotto. Campinas: Mercado de Letras; São Paulo: Educ, 2002.

Magalhães, I. Análise de discurso crítica: questões e perspectivas para a América Latina. In: Resende, V. de M. \& Pereira, F. H. (Orgs.). Práticas socioculturais e discurso: debates transdisciplinares. Covilhã: LabCom Books, 2010, p. 9-28. Magalhães, I. Introdução: a Análise de Discurso Crítica. D.E.L.T.A., v. 21, n. Esp., São Paulo: EDUC, p. 1-11, 2005.

Marcuschi, L. A. Gêneros textuais: definição e funcionalidade. In: Dionísio, A. P.; Machado, A. R. \& Bezerra, M. A. (Org.). Gêneros textuais e ensino. Rio de Janeiro: Lucerna, 2005, p. 19-36. 
Nascimento, A. C. Propaganda de medicamentos. É possível regular? Tese de doutorado. Universidade do Estado do Rio de Janeiro. Instituto de Medicina Social, 2007.

Ramalho, V. Dizer sem ter dito: sentidos implícitos em publicidades de medicamento. REVISA - Revista brasileira de vigilância sanitária, 2 (1): 31-40, 2006.

Ramalho, V. Construindo uma pesquisa em Análise de Discurso Crítica: da ontologia à metodologia. In: Resende, V. de M. \& Pereira, F. H. (Orgs.). Práticas socioculturais e discurso: debates transdisciplinares. Covilhã: LabCom Books, 2010, p. 223-255.

Ramalho, V. 'Magra sem pesar no bolso': discurso e ideologia na propaganda de medicamentos. In: Silva, D. E. G. da; Leal, M. C. D.; Pacheco, M. C. N. (Orgs.) Discurso em questão: representação, gênero, identidade, discriminação. Goiânia: Cânone, 2009a, p. 189-200.

Ramalho, V. Análise de Discurso e Realismo Crítico: princípios para uma abordagem crítica explanatória do discurso. In: Anais da XII Conferência Anual da IACR - International Association for Critical Realism. Universidade Federal Fluminense (UFF), Niterói, 2009b. CD ROM v. XII (s.p.). Disponível em: http://www.uff.br/iacr/. Acesso em 30 set. 2009.

Ramalho, V. Diálogos teórico-metodológicos: Análise de Discurso Crítica e Realismo Crítico. Cadernos de Linguagem e Sociedade, v. 8, p. 78-104, 2007.

Ramalho, V. Discurso e ideologia na propaganda de medicamentos: um estudo crítico sobre mudanças sociais e discursivas. Tese de doutorado. Universidade de Brasília. Programa de Pós-Graduação em Linguística, 2008.

Resende, V. de M. Análise de discurso crítica e Realismo Crítico: implicações interdisciplinares. Campinas: Pontes, 2009.

Resende, V. de M. \& Ramalho, V. Análise de Discurso Crítica: uma reflexão acerca dos desdobramentos recentes da teoria social do discurso. ALED/Revista Latinoamericana de Estudios del Discurso, v. 5, n. 1, p. 27-50, 2005.

Resende, V. de M. \& Ramalho, V. Análise de Discurso Crítica. São Paulo: Contexto, 2006. $1^{\text {a }}$ reimpressão 2009.

Sampaio, R. Propaganda de A a Z. Rio de Janeiro: Elsevier, 2003.

Silva, D. E. G. da \& Ramalho, V. Análise de Discurso Crítica: representações sociais na mídia. In: Lara, G. M. P.; Machado, I. L. \& Emediato, W. (Orgs.). Análise de discurso hoje, v.2, Rio de Janeiro: Nova Fronteira; Lucerna, 2008a, p. 265-292. 
Silva, D. E. G. da \& Ramalho, V. Reflexões para uma abordagem crítica dos gêneros discursivos. ALED/Revista Latinoamericana de Estudios del Discurso, v. 8 (1), 2008b, p. 19-40.

Silva, D. E. G. da. A pobreza no contexto brasileiro: da exclusão econômica e social à ruptura familiar. Revista Iberoamericana de Discurso y Sociedad, v. 2, p. 1887-4706, 2008.

Silva, D. E. G. da. Identidades enfraquecidas versus cidadania cultural. In: Joachin Sèbastien (Org.). Diversidade cultural, linguagens e identidades. Recife: Elógica, vol. 1, 2007a, p. 51-68.

Silva, D. E. G. da. Critical Discourse Analysis and the functional bases of language. In: Barbara, L. \& Sardinha, T. B. (Ed.). Proceedings of the 33rd International Systemic Functional Congress (PUC/SP), p. 932-949, 2007b.

Silva, D. E. G. da. Representações discursivas da pobreza e gramática. DELTA. Documentação de Estudos em Linguística Teórica e Aplicada (PUC/SP), v. 25, p. 721-731, 2009.

Silva, T. T. da. Nós, ciborgues: o corpo elétrico e a dissolução do humano. In: (Org./Trad.). Antropologia do ciborgue: as vertigens do pós-humano. Belo Horizonte: Autêntica: 2000, p. 11-17.

Silva, Z. P. da. Controle Sanitário: construção e desconstrução de sentidos. Tese de doutorado. Universidade de Brasília. Programa de Pós-Graduação em Linguística, inédito.

Silva, Z. P. da; Coroa, M. L. M. S. Vigilância Sanitária: um histórico discursivo. REVISA. Revista Brasileira de Vigilância Sanitária, v. 1, p. 3-16, 2005.

Temporão, J. G. A propaganda de medicamentos e o mito da saúde. Rio de Janeiro: Graal, 1987.

Thompson, J. B. Ideologia e cultura moderna: teoria social crítica na era dos meios de comunicação de massa. Trad. (Coord.) Pedrinho A. Guareschi. Petrópolis: Vozes, 2002.

Vestergaard, T. \& Schrøder, K. A linguagem da propaganda. Trad. João Alves dos Santos. São Paulo: Martins Fontes, 1994.

Wodak, R. Do que trata a ACD - um resumo de sua história, conceitos importantes e seus desenvolvimentos. Linguagem em (Dis)curso, v. 4, n. especial Análise Crítica do Discurso, p. 223-243, 2004. 